\title{
Colonoscopy - Effective in Solving Diagnostic Dilemmas
}

\author{
Vani Malhotra*, Parveen Malhotra, Smiti Nanda, Vandana Rani, Meenakshi Chauhan and Isha Pahuja \\ Department of Gynecology \& Obstetrics, Medical Gastroenterology, India
}

Submission: June 06, 2019; Published: July 19, 2019

"Corresponding author: Vani Malhotra, Department of Medical Gastroenterology, Gynaecology \& Obstetrics, PGIMS, 128/19, Civil Hospital Road, Rohtak, Haryana, India

\begin{abstract}
Introduction: Enterobius Vermicularis is the most common helminth infecting man with a host range restricted to humans. The parasite is not transmitted by arthropod vectors or intermediate hosts but directly from the parasitized subject to a healthy subject by means of infected hands, food or fomites.

Observation: A 35 year old woman presented to gynaecology department with the complaint of vaginal and perianal itching, pain abdomen, fever and generalized weakness for last one month. She was initially managed at some private hospital where Contrast Computed Tomography abdomen and pelvis was done due to refractory pain abdomen which revealed multiple metallic like foreign objects in anal canal and rectum.

Results: Patient was admitted for proper evaluation and after initial symptomatic treatment and stabilization was subjected to colonoscopy which revealed multiple worms in Anal Canal and Rectum, few of which were retrieved for examination and confirmation of type of worm. The patient was dewormed and within three days responded to treatment and was discharged under hemodynamically stable condition.

Conclusion: Delayed treatment for simple diseases like worm infestation can lead to toxic manifestations and colonoscopy aids in computed tomography scan in making proper diagnosis treatment.

Keywords: Enterobius Vermicularis; Colonoscopy; Computed tomography; Perianal itching; Generalized weakness; Fever; Pain Abdomen; Rectum; Anal; Psychiatric disorder; Appendicular lumen; Intestinal wall; Liver; Lungs; Epidydimis
\end{abstract}

\section{Introduction}

Enterobius Vermicularis is the most common helminth infecting man with a host range restricted to humans [1]. The parasite is not transmitted by arthropod vectors or intermediate hosts but directly from the parasitized subject to a healthy subject by means of infected hands, food or fomites [2]. Indirect transmission by air has been noted wherein suspended microscopic eggs get inhaled with dust. Gravid adult worms often migrate to the anus during night and in female patients may enter the vagina to release eggs and cause vulvovaginitis [3]. We are reporting an interesting case of 35-year-old female who presented with persistent vulvovaginitis, perianal itching, generalized weakness, fever and pain abdomen. Contrast abdomen and pelvis was done for evaluation of pain abdomen which revealed multiple minute foreign bodies in rectum and anal area.

\section{Case Report}

A 35-year-old woman presented to gynaecology department with the complaint of vaginal and perianal itching, pain abdomen, fever and generalized weakness for last one month. She was initially managed at some private hospital where Contrast Computed Tomography abdomen and pelvis was done due to refractory pain abdomen which revealed multiple metallic like foreign objects in anal canal and rectum. There she was suspected to be suffering from psychiatric disorder and thus was being evaluated for habit of putting some foreign objects in her anal canal and vagina. At this juncture, patient was admitted for proper evaluation and at time of admission she was toxic as evidenced by fever, leucocytosis and was anemiac. She was initially treated with intravenous fluids, antibiotics, two units of whole blood and after stabilization was subjected to colonoscopy which revealed multiple worms in anal Canal and rectum, few of which were retrieved for examination and were confirmed to be enterobius vermicularis i.e. pinworm. The patient was dewormed and within three days responded to treatment and was discharged under hemodynamically stable condition (Figure $1 \& 2$ ). 


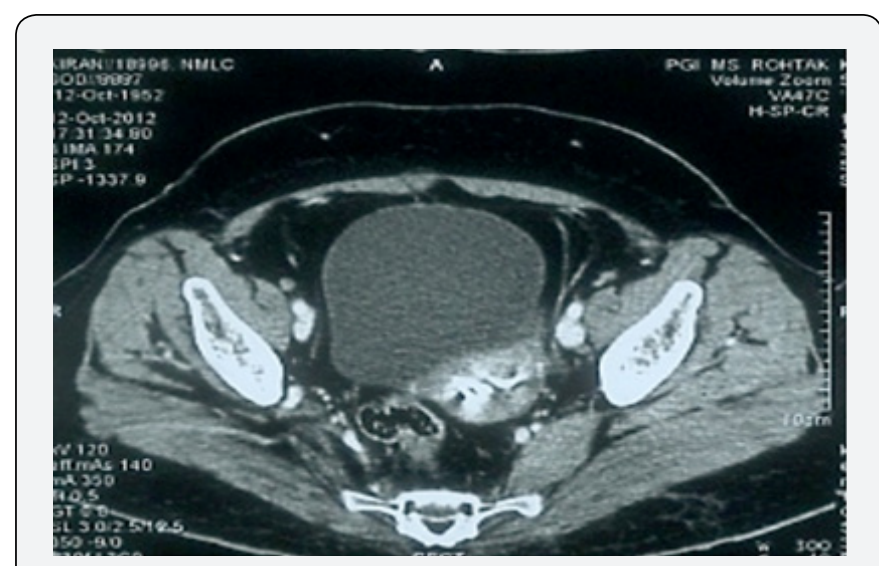

Figure 1: Computed Tomography Scan Showing Multiple Enterobius Worms in Rectum Mimicking Mettalic Objects.

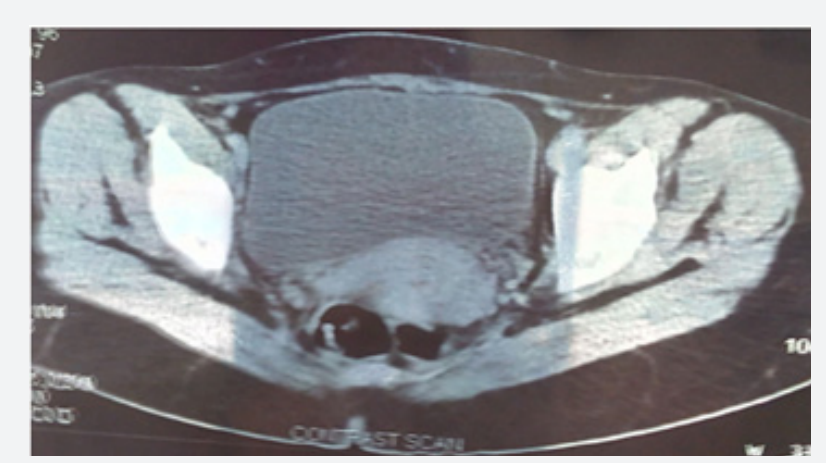

Figure 2: CT Scan Showing Two Worms Mimicking Mettalic Objects.

\section{Discussion}

Enterobius Vermicularis is an intestinal nematode most often encountered in the temperate zones especially in areas of poor fecal sanitation. During the cycle of the parasite the female once fertilized descends into the rectum from its habitual location, the cecum and the colon and lays its eggs in the anal folds and the surrounding areas. The deposited eggs mature in few hours and contain fully developed larvae becoming infective. The movements of the females and laying of the eggs cause itching [3]. Predisposing the passage of the infection to the same person or the other persons through hands which have been contaminated in this way. In female subjects, E.vermicularis can sometimes take another path and be found in the genitals, going from the vulva back up to the fallopian tubes, sometimes reaching the ovaries and also having the capacity of penetrating the surrounding peritoneum. Sometimes the parasite can go into rare ectopic locations such as the tissues of perianal region, the prostrate, the urinary bladder, the ureter, the spleen, the peritoneum, the mucosa and/or the appendicular lumen, intestinal wall, liver, lungs, epidydimis and the conjunctival sac. In such cases, the clinical diagnosis is impossible and the diagnosis is reached only histologically $[4,5]$. Diagnosis is usually made by looking at the typical plano-convex eggs of size $50-60 \mu$ in length, $20-30 \mu$ in width with thick double- contoured hyalinised sheath. NIH swab, cellophane swab or scrotch tape swab method is used to collect the eggs from the perianal skin. Stool examination may not be helpful at times because eggs are not released in the feces. Occasionally eggs are detected in the urine and vaginal smears [6]. The adult worms are identified by the double-bulb oesophagus and a pair of cervical alae in the anterior end. Infected children and adults should be treated with mebendazole $(100 \mathrm{mg}$ once), albendazole (400 mg once), or pyrantel pamoate $(11 \mathrm{mg} / \mathrm{kg}$ once; maximum $1 \mathrm{~g}$ ) with same treatment repeated after 2 weeks. Whole family of the infected person has to be treated to eradicate the reservoir of infection. Good personal hygiene, proper disposal of human excreta and rural health education is necessary to control and prevent enterobiasis.

\section{Conclusion}

Delayed treatment for simple diseases like worm infestation can lead to toxic manifestations and colonoscopy aids in computed tomography scan in making proper diagnosis as well as treatment.

\section{References}

1. Wong JY, Becker SN (1982) Enterobius Vermicularis ova in routine cervicovaginal smears: Light and scanning electron microscopic observations. Acta Cytol 26(4): 484-487.

2. Craggs B, De Waele E, De Vogelaere K, Wybo I, Laubach M, et al. (2009) Enterobius Vermicularis with tuboovarian abscess and peritonitis occurring during pregnancy. Surg Infect 10: 545-547.

3. Parija SC (2006) Hookworms and other Bursate Nematodes, Oxyruid and Ascarid Nematodes. In: Parija SC, (Edt.), Textbook of Medical Parasitology- Protozology and Helminthology, (3 ${ }^{\text {rd }}$ edn.), New Delhi: All India, Publishers and Distributors, pp. 313-316.

4. Mattia AR (1992) Perianal mass and recurrent cellulites due to Enterobius Vermicularis. Am J Trop Med Hyg 47: 811-815.

5. Babady NE, Awender E, Geller R, Miller T, Scheetz G, et al. (2011) Enterobius Vermicularis in a 14-year-old girl's eye. J Clin Microbiol 49(12): 4369-4370.

6. Sheety JB, Kulkarni DV, Prabhu VL (2012) Eggs containing larvae of Enterobius Vermicularis in vaginal smear. J Cytol 29(1): 94-96.

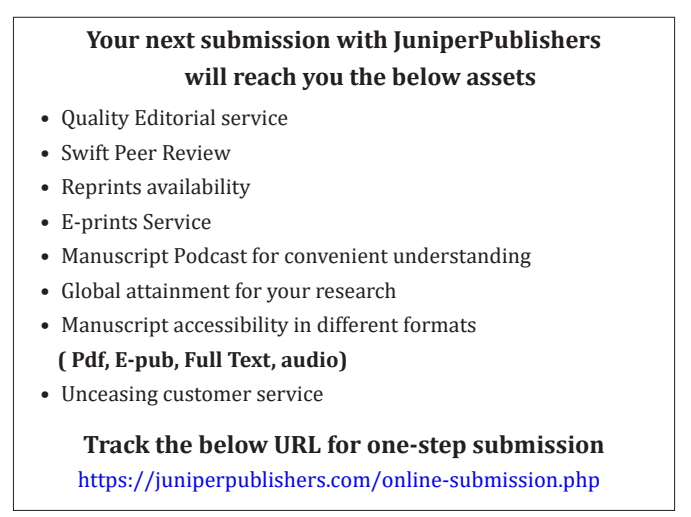

